УДК 316.477; 316.61; 378.1

ББК 60.53

DOI: $10.35211 / 2500-2635-2020-4-44-36-44$

МАГИСТРАНТ ТЕХНИЧЕСКОГО ВУЗА

\title{
MASTER STUDENTS OF A TECHNICAL UNIVERSITY
}

\section{КАРЧАГИН ЕвгенИй Владимирович}

Волгоградский государственный

технический университет, Водгоград, Россия

E-mail: evgenkar@yandex.ru

\section{ГАЯЕНКО Майя Владимировна}

Волгоградский государственный

технический университет, Водгоград, Россия

E-mail: mayagalenko@mail.ru

\section{KARCHAGIN Evgenij V.}

Volgograd State Technical University,

Volgograd, Russia

E-mail: evgenkar@yandex.ru

\section{GALENKO Maja V.}

Volgograd State Technical University, Volgograd, Russia

E-mail: mayagalenko@mail.ru

(C) Карчагин Е. В., Галенко М. В., Янин К. Д, 2020. 


\section{ЯНИН Кирилд Дмитриевич}

Волгоградский государственный технический университет, Волгоград, Россия

E-mail: yshamana3ryki@mail.ru

Аннотация. В статье анализируются социаль-нопсихологчческие качества российских студентов магистратуры технического вуза. С 2003 г. Российская образовательная система ориентируется на болонскую программу, подразумеваюшую переход на двухступенчатую модель. При этом студенты магистратуры остаюотся малоизученныл предметом со стороны науки. Социально-психологическое портретирование магистранта представляет собой важную задачу по мониторингу современного состояния процесса подготовки кадров высшей квалификации. Проведенное в 2020 2. исследование показало, что полученный обобщенный портрет демонстрирует, что студенты магистратурь обладают способностями, которые могут быть направлены как на управленческую деятельность, так и на инновационно-научную. При этом явно выраженная интровертивность не позволяет говорить о приоритетности управленческой деятельности. Тем самыли на данный момент вызывает затруднение задача прогонозирования предпочтительного ведущего типа деятельности после окончания магистратурьл.

Кдючевые слова: магистратура, методика Кеттелла, социально-психологический портрет, магистрант технического вуза, технический вуз.

\section{YANIN Kirill D.}

Volgograd State Technical University, Volgograd, Russia E-mail: yshamana3ryki@mail.ru

Abstract. The article analyzes the sociopsychological qualities of Russian master students at a technical university. Since 2003 the Russian educational system is guided by the Bologna program, which implies a transition to a two-stage model. At the same time, master students remain a little-studied subject. Socio-psychological portraiture of undergraduates is an important task for monitoring the current state of the process of training highly qualified personnel. The research showed that the resulting generalized portrait shows that master students have abilities that can be directed both to managerial activities and to scientific ones. At the same time, clearly expressed introversion does not allow us to speak about the priority of management activities. Thus, at the moment, the problem of predicting the preferred leading type of activity after the master's degree is difficult.

Keywords: magistracy, Cattell method, sociopsyc-hological portrait, master student of a technical university, technical university.

Сегодня российское высшее образование ориентировано на болонскую систему, которая предполагает базовую подготовку студентов сначала в рамках бакалавриата или специалитета, а затем в магистратуре. Согласно болонской системе, высшее образование, которое ранее было «сплошным», становится двухуровневым. Магистратура становится вторым уровнем высшего образования, позволяющим получить дополнительную квалификацию или углубить знания по уже имеющейся профессии. Целью перестройки образовательной системы был переход к общеевропейским стандартам, что могло бы расширить академические и карьерные возможности студентов. Официальной датой начала процесса по унификации систем образования стран Евросоюза считается 19 июня 1999 г., когда в Болонье министры образования почти тридцати государств подписали декларацию «Зона европейского высшего образования». Российская Федерация примкнула к болонской декларации в сентябре 2003 г.

Однако переход на новую систему в России нельзя считать беспроблемным. Как отмечают М.Ю. Прахова и С.В. Светлакова, корнем большинства проблем, связанных с новой двухступенчатой системой высшего образования в России, является по сути механический переход к ней, без должной глубины осмысления и проработки, без внимания к сложившимся традициям: «На момент присоединения к Болонскому процессу отсутствовала четкая и внятная концепция как бакалавриата, так и магистратуры, оценка их пригодности для тех или иных сфер профессиональной деятельности» (2014: 122).

Тем самым вырисовывается весьма неоднозначная ситуация в современной российской системе подготовки магистров и в понимании образа современного студента магистратуры. Если студенчество составдяет давний 
предмет социологических и психологических исследований, то российские магистранты ввиду понятных причин еще недостаточно получили научного внимания. Так, исследовались: социальный портрет магистранта (Бесчасная 2019), мотивация к процессу обучения в магистратуре (Дарханова, Портнягина 2017), вопросы формирования компетенций межкультурных взаимодействий (Мещерякова 2019) и др. Важной задачей остается изучение личностных, социально-психологических особенностей магистрантов российских вузов. В своей статье мы обратидись к исследованию данных особенностей у студентов магистратуры технического вуза.

Нормативные документы обрисовывают следующий образ магистранта, после получения им магистерской степени.

Согласно ФГОС, основные виды профессиональной деятельности, на которые нацелена подготовка магистрантов технического профиля (08.04.01 Строительство) это: «инновационная, изыскательская и проектно-расчетная; производственно-технологическая; научно-исследовательская и педагогическая; по управлению проектами; профессиональная экспертиза и нормативно-методическая» (Приказ Минобрнауки России...). Иными словами, магистратура в рамках высшего инженерно-технического образования: «должна обеспечить подготовку высококвалифицированных специалистовисследователей, готовых к инновационной деятельности в инженерном деле» (Сенашенко, Конькова, Васильева 2012: 21).

Согласно тому же документу ФГОС, подразумевается сосуществование двух разновидностей магистерских программ: 1) академической («ориентированной на научно-исследовательский и (или) педагогический вид (виды) профессиональной деятельности как основной»); 2) прикладной («ориентированной на производственно-технологический, практико-ориентированный, прикладной вид (виды) профессиональной деятельности как основной») (Приказ Минобрнауки России...).

Тем самым подразумевается, что у магистерской подготовки есть две основные цели: 1) подготовка научно-педагогических кадров; 2) подготовка производственных кадров. Однако, как отмечает С.Н. Постников, вторая цель фактически реализуется как адаптация программ МВА и готовит будущих руководителей, но: «не высококвалифицированных специалистов (которыми становятся по мере накопления опыта на рабочем месте и по средством систематического повышения квалификации и прохождения программ корпоративного обучения)» (2016: 48). Это говорит о том, что обучение в магистратуре сегодня способно развивать узкопрофильные и аналитические компетенции и позволяет сформировать фундамент для научной или управленческой деятельности (но в меньшей степени для сугубо производственной).

Однако данный потенциал реализуется в текущей действительности совсем неравномерно. Как показывают недавние исследования И.Б. Стукаловой: «проблемной зоной образовательных программ магистратуры является их «академизм». <..> Если же магистерская программа имеет практическую ориентацию, она все равно «перегружена» научно-исследовательской со- 
ставляющей» (Стукалова 2018). По ее данным: «Только 7\% абитуриентов магистерских программ хотели бы поступить на академические программы для дальнейшего продолжения обучения в аспирантуре» (Там же). Иными словами, даже при наличии «академического крена» российских магистерских программ, большинство абитуриентов не стремятся ориентировать свою жизнь на научно-преподавательскую деятельность. Сходную картину дает О.В. Мотовилов: «дишь 13\% опрошенных автором выпускников магистратуры, обучавшихся по программе академически-ориентированной модели, планируют в будущем заняться исследовательской деятельностью» (2016: 42).

В связи с этим гипотеза проведенного нами исследования заключалась в том, что магистранты технического вуза будут демонстрировать невысокие показатели свидетельствующие о способности заниматься научной и педагогической деятельностью (то есть прежде всего интелдектуальные способности), а будут более ориентированы на непосредственное производство (как высококлассные специалисты или управленцы) и, следовательно, будут обладать высокими коммуникативными и организаторскими данными.

Для проверки сформулированной гипотезы и диагностики психологического портрета студента магистратуры технического вуза мы применили методику многофакторного исследования дичности Кеттела (Cattell), одного из наиболее популярных в мире тестов для определения дичностных черт. Опросник Кеттелла состоит из 187 суждений, поделенных на 16 групп шкал (факторов), измеряющих биполярные свойства личности. Каждая из этих шкал оценивает отдельную черту личности в баллах (Капустина 2001).

Тестирование прошли 45 магистрантов, обучающихся в магистратуре Волгоградского технического университета по направлению 08.04.01 Строительство (Табл. 1).

Таблица 1

Распределение респондентов по полу, \%

\begin{tabular}{|l|c|c|}
\hline \multicolumn{1}{|c|}{ Пол } & Частота & Валидный процент \\
\hline Мужской & 32 & 71,1 \\
\hline Женский & 13 & 28,9 \\
\hline Итого & 45 & 100,0 \\
\hline
\end{tabular}

Собранные данные были обработаны при помощи программы SPSS, в результате чего мы получиди среднестатистические показатели по каждой из шестнадцати шкал (Табл. 2). Критерий Колмогорова-Смирнова демонстрирует принадлежность всех результатов (кроме фактора Е) к нормальному распределению (то есть асимптотическая значимость больше 0,05).

Статистическая обработка данных позволила обрисовать обобщенный психологический портрет магистранта. 
Описатедьные статистики по 16 факторам методики Кеттедла

\begin{tabular}{|c|c|c|c|c|c|c|}
\hline Факторы & $\mathrm{N}$ & Среднее & $\begin{array}{c}\text { Стандартное } \\
\text { откдонение }\end{array}$ & Минимум & Максимум & $\begin{array}{c}\text { Асимпт. знч. } \\
\text { (двухсторонняя) }\end{array}$ \\
\hline $\mathrm{A}$ & 45 & 5,51 & 1,950 & 1 & 10 & 0,130 \\
\hline $\mathrm{B}$ & 45 & 5,93 & 1,935 & 2 & 10 & 0,107 \\
\hline $\mathrm{C}$ & 45 & 5,73 & 2,462 & 2 & 10 & 0,693 \\
\hline $\mathrm{E}$ & 45 & 5,82 & 1,466 & 3 & 10 & 0,042 \\
\hline $\mathrm{F}$ & 45 & 3,89 & 1,761 & 1 & 9 & 0,150 \\
\hline $\mathrm{G}$ & 45 & 5,71 & 2,139 & 1 & 10 & 0,466 \\
\hline $\mathrm{H}$ & 45 & 5,47 & 2,361 & 1 & 10 & 0,406 \\
\hline $\mathrm{I}$ & 45 & 5,47 & 1,700 & 3 & 10 & 0,406 \\
\hline $\mathrm{L}$ & 45 & 6,13 & 2,029 & 1 & 10 & 0,119 \\
\hline $\mathrm{M}$ & 45 & 5,58 & 2,050 & 2 & 10 & 0,203 \\
\hline $\mathrm{N}$ & 45 & 5,53 & 1,866 & 2 & 10 & 0,157 \\
\hline $\mathrm{O}$ & 45 & 5,38 & 2,259 & 1 & 9 & 0,509 \\
\hline $\mathrm{Q} 1$ & 45 & 6,04 & 2,266 & 1 & 10 & 0,432 \\
\hline $\mathrm{Q} 2$ & 45 & 5,89 & 1,921 & 1 & 10 & 0,166 \\
\hline $\mathrm{Q} 3$ & 45 & 7,51 & 1,792 & 3 & 10 & 0,158 \\
\hline $\mathrm{Q} 4$ & 45 & 5,60 & 2,082 & 1 & 10 & 0,075 \\
\hline
\end{tabular}

Как видно из таблицы показатели так называемой «большой пятерки» факторов (А, F, Н, N, Q2 - общительность, экспрессивность, смелость, дипломатичность и нонконформизм), наиболее устойчивой и универсальной для разных языковых культур, демонстрируют средние значения. И в целом полученные данные показывают в основном усредненный баля (между 5 и 6). Искдючение составдяют характеристики Фактора L (доверчивость - подозрительность) - 6,13 и Фактора Q1 (консерватизм - радикализм) - 6,04. Самое высокое значение получил Фактор Q3 (самоконтроль) - 7,51. Самое низкое значение получил фактор F (сдержанность - экспрессивность). Тем самым ведущими особенностями в структуре обобщенного портрета дичности студентов магистратуры явдяются факторы сдержанности, подозрительности, радикализма и высокого самоконтроля.

Представленные в Таблице 3 значения показывают наиболее часто встречающийся балд в ответах респондентов. Как видно, эти данные не сильно отличаются от обобщенной картины. Однако обращает на себя внимание низкий балд по шкале Н (застенчивость - смелость) и увеличение балла в шкалах В (мышление), С (эмоциональная стабильность), G (высокая нормативность поведения) и Q1 (радикализм), хотя и не до самых высоких значений. 
Профиль дичности (максимадьные значения)

\begin{tabular}{|c|c|c|c|c|c|c|c|c|c|c|c|}
\hline & 1 & 2 & 3 & 4 & 5 & 6 & 7 & 8 & 9 & 10 & \\
\hline А Закрытость & & & & & - & & & & & & Открытость \\
\hline $\begin{array}{l}\text { В Конкретное } \\
\text { мышление }\end{array}$ & & & & & & & & & & & $\begin{array}{l}\text { Абстрактное } \\
\text { мышление }\end{array}$ \\
\hline $\begin{array}{l}\text { С Эмоциональная } \\
\text { неустойчивость }\end{array}$ & & & & & & & & & & & $\begin{array}{l}\text { Эмоциональная } \\
\text { стабильность }\end{array}$ \\
\hline Е Подчиненность & & & & & & & & & & & Ломинантность \\
\hline F Сдержанность & & & & $\bullet$ & & & & & & & Экспрессивность \\
\hline $\begin{array}{ll}\mathrm{G} & \text { Низкая } \\
\text { нормативность }\end{array}$ & & & & & & & & & & & $\begin{array}{l}\text { Высокая } \\
\text { нормативность }\end{array}$ \\
\hline Н Застенчи вость & & & $\bullet$ & & & & & & & & Смелость \\
\hline I Жестокость & & & & & 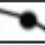 & & & & & & Чувствительность \\
\hline L Доверчивость & & & & & & 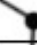 & & & & & Подозрительность \\
\hline М Практичность & & & & & & 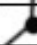 & & & & & Мечтательность \\
\hline $\begin{array}{l}\mathrm{N} \\
\text { Прямолинейность }\end{array}$ & & & & & & & & & & & Дипломатичность \\
\hline О Спокойствие & & & & & 6 & & & & & & Тревожность \\
\hline Q1 Консерватизм & & & & & & & $\bar{x}$ & & & & Радикализм \\
\hline Q2 Конформизм & & & & & $\bullet$ & & & & & & Нонконформизм \\
\hline 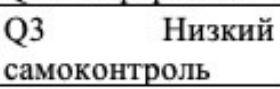 & & & & & & & & & & & $\begin{array}{l}\text { Высокий } \\
\text { самоконтроль }\end{array}$ \\
\hline $\begin{array}{l}\text { Q4 } \\
\text { Расслабленность }\end{array}$ & & & & & & & & & & & Напряженность \\
\hline & 1 & 2 & 3 & 4 & 5 & 6 & 7 & 8 & 9 & 10 & \\
\hline
\end{tabular}

Отметим еще большое количество показателей (по восьми шкалам и более) со средними значениями, что может быть вызвано тем, что испытуемые давади ответы, исходя из социальной желательности иди их противоречивые ответы показывают отсутствие склонности к самоанализу, привычки задумываться о мотивах собственного поведения. В конечном счете, это может говорить о том, что магистранты еще плохо определидись в жизни и / или их личность находится еще в процессе формирования.

Обратимся к более детальному анализу полученной картины. Низкие значения социально-психологических факторов А-, F-, Н- демонстрируют эмоционадьную сдержанность в междичностных контактах, трудности в преодолении коммуникативных барьеров, нацеленность на внутренний мир и индивидуадьную работу, общую замкнутость, то есть могут свидетельствовать о психологической интроверсии. Средние значения факторов А (4-7) и Н (4-7) характеризуют человека, который не способен проявлять высокой собственной активности в формировании контактов с другими июдьми. Человек может проявить собственную инициативу в общении только в случае острой необходимости, например, если напрямую затрагиваются его личные интересы. Часто такой человек проявляет высокую избиратедьность в общении, и в целом имеет небольшой круг близких ему людей. Общение с «внешними» требует усилий для преодоления тревоги и психоэмоционального напряжения. Учитывая 3 балла по шкале Н как наиболее популярный у испытуемых, можно сказать, что им свойственны робость, нере- 
шительность, застенчивость, сдержанность, некоторая бояздивость, такие люди стараются строго придерживаться установленных правил, предпочитают находиться в тени, избегают большого общества дюдей.

Эмоциональные способности С, О демонстрируют эмоциональную уравновешенность, которая при настороженном отношением к людям и стремлением к независимости способствует сохранению социальной дистанции. Личностные факторы I, М, О говорят о невысокой эмоциональной чувствительности и большей прагматической ориентации, связанной с конкретной действительностью и практической деятельностью.

Так, в сфере интеллектуальных способностей (сочленение факторов В, M, Q1) у магистрантов обнаружен достаточно высокий уровень развития иогического мышления, способностей к математике и общей обучаемости. Им присуща эрудированность, оперативность, подвижность мышления, достаточно высокий общекультурный уровень. Эти дюди обладают воображением, критичностью и направлены на конкретное практическое мышление, при этом сохраняя интерес к экспериментированию и нововведениям в своей профессиональной области.

Следует обратить внимание на высокие балды фактора Q3, измеряющий степень поведенческого самоконтроля (в оригинале - perfectionism). Высокие балды данного фактора показывают, что их обладатели являются людьми с хорошо развитой волей и целеустремленностью, способные к самоконтродю и точности в выполнении социальных требований и правил поведения. По данному фактору можно судить о важности карьеры и профессиональной репутации для магистрантов. С учетом факторов С и G, можно сказать, что они также наиболее склонны к административной работе и смогут достичь положительных результатов в профессиях, где требуются ответственность, решительность и эмоциональная уравновешенность. В целом, фактор Q3 демонстрирует выраженность волевых качеств человека. Он является важнейшим для прогнозирования эффективности и продуктивности дальнейшей профессионадьной деятельности. Он связан с возможностью стать лидером рабочего колдектива и высокой активностью в разрешении трудовых и научных задач.

Таким образом, полученный обобщенный психологический портрет показывает, что студенты магистратуры обладают способностями, которые могут быть направлены как на управленческую деятельность, так и на инновационно-научную, поскольку демонстрируют достаточно хороший уровень решения интеллектуальных задач. При этом явно выраженная интровертивность не позволяет говорить о приоритетности управленческой деятельности. Наиболее оправданно утверждать, что психограмма магистранта схватывает текущую образовательную деятельность и дает достаточно адекватный портрет студента, способного к освоению содержания преподаваемых дисципдин. Тем самым на данный момент вызывает затруднение задача прогнозирования предпочтительного ведущего типа деятельности после окончания магистратуры. Как утверждают Т.М. Дарханова и М.А. Портнягина, современные российские магистранты не всегда хорошо осознают как 
смысл своего пребывания в магистратуре, так и возможных траекторий своей жизни после того, как обучение было завершено: «Двухуровневая система высшего профессионального образования для них все еще не совсем понятна, место магистратуры в профессиональном становлении специалиста они не видят. Как правило, магистратура для них является ступенью, позвоияющей личностно развиваться и совершенствоваться. Выбранные мотивы социально не значимы для общества и направлены Аишь на ... соответствие стандартам образования» (2017: 128).

Ввиду этого можно рекомендовать как практические, так и теоретические шаги. В практическом пиане можно рекомендовать проведение социально-психодогического мониторинга студентов-магистрантов при поступлении и на всех этапах обучения в магистратуре, чтобы получить более объемное представление о трудностях и успехах в процессе развития и реализации научных или управленческих способностей. Для более эффективного осуществдения этих задач оправданно также ввести для обучения в магистратуре специальные психологические курсы. Это может быть «Психология», «Социальная психология», «Психологические особенности профессионадьной деятельности» или «Психология управления дичностными ресурсами» (в зависимости от решения руководства вуза). Данные дисциплины помогди бы обеспечить формирование знаний, умений и мотивов, способствующих личностному развитию и профессиональному самоопределению, компетенции самообразования, а также готовности магистрантов к коллективной, управленческой деятельности и к научной работе.

В теоретическом плане представляются оправданными дальнейшие исследования дичностных качеств студентов технической магистратуры, в особенности мотивационной структуры. Кроме того, желательно дополнять социально-психологические данные социально-демографическими, а также проводить сравнительное изучение магистрантов разных специальностей, что позводить создать многомерный профиль современного магистранта технического вуза.

\section{ИСПОЯЬЗОВАННЫЕ ИСТОЧНИКИ}

1.Бесчасная, А.А. Социальный портрет студента как компонент мониторинга качества организации образовательного процесса / А.А. Бесчасная // ДИСКУРС. - 2019. - Т. 5, № 5. C. 64-75.

2. Дарханова, Т.М. Изучение мотивов поступления в магистратуру в контексте повышения качества образования у студентов / Т.М. Дарханова, М.А. Портнягина // Вестник бурятского государственного университета. - 2017. №. - 7. - С. 122-129.

3. Капустина, А.Н. Многофакторная дичностная методика Р. Кеттелла / А.Н. Капустина. СПб. : Речь ; М. : Ин-т психотерапии и клин. психологии, 2001. - 99 с.

4. Мещерякова, Е.В. Проблемы формирования компетенций у магистрантов в социокультурном языковом пространстве вуза (на примере Волгоградского региона) / Е.В. Мещерякова // Primo aspectu. - 2019. - № 1. С. 93-98

5. Мотовилов, О.В. Проблемы подготовки кадров в магистратуре / О.В. Мотовилов // Высшее образование в России. - 2016. - № 2 (198). - С. 38-45.

6. Постников, С.Н. Сквозная модель магистерской подготовки в инженерной области / С.Н. Постников // Высшее образование в России. - 2016. - № 2 (198). - С. 46-53. 
7. Прахова, М.Ю. Подготовка магистров в инженерной области: отечественная модель / М.Ю. Прахова, С.В. Светлакова // Высшее образование в России : научно-педагогический журнал. - 2014. - № 1. - С. 118-124.

8. Приказ Минобрнауки России от 30.10.2014 N 1419 «Об утверждении федерального государственного образовательного стандарта высшего образования по направлению подготовки 08.04.01 Строительство (уровень магистратуры)». - [Электронный ресурс]. - Режим доступа: http://fgosvo.ru/uploadfiles/fgosvom/080401_Stroitelstvo.pdf (дата обращения 05.05.2020 г.).

9. Сенашенко, В.С. Роль и место магистратуры в современной модели инженерного образования / В.С. Сенашенко, Е.А. Конькова, С.Е. Васильева // Высшее образование в России. 2012. - № 11. - С. 16-22.

10. Стукалова, И.Б. Развитие магистратуры в России: предпосылки, проблемы и перспективы / И.Б. Стукалова // Современное образование. - 2018. - № 3. - С. 1-8. 